\title{
Optimizing pulsed current micro plasma arc welding parameters to maximize ultimate tensile strength of Inconel625 Nickel alloy using response surface method
}

\author{
Kondapalli Siva Prasad ${ }^{a^{*}}$, Chalamalasetti Srinivasa Raob ${ }^{b}$ Damera Nageswara Rao ${ }^{c}$ \\ ${ }^{a}$ Department of Mechanical Engineering, Anil Neerukonda Institute of Technology \& Sciences, Visakhapatnam, 531 162,INDIA \\ ${ }^{b}$ Department of Mechanical Engineering , Andhra University, Visakhapatnam,530 002, INDIA \\ ${ }^{c}$ Vice Chancellor, Centurion University, INDIA \\ *Corresponding Author Email:kspanits@gmail.com, Contact No: 91-9849212391, Fax No: 91-08933-226395
}

\begin{abstract}
This paper reveals the influences of pulsed current parameters namely peak current, back current, pulse and pulse width on the ultimate tensile strength of Micro Plasma Arc Welded Inconel 625 sheets. Mathematical model is developed to predict ultimate tensile strength of pulsed current micro plasma arc welded Inconel 625 sheets. Four factors, five level, central composite rotatable design matrix is used to optimize the number of experiments. The mathematical model has been developed by using Response Surface Method. The adequacy of the developed model is checked by using Analysis of Variance technique. By using the developed mathematical model, ultimate tensile strength of the weld joints are predicted with $99 \%$ confidence level. Validation experiments are conducted to validate the predicted values of the developed mathematical model. From the contour plots, it is understood that ultimate tensile strength is more sensitive to peak current and pulse. Also it is found that peak current is most dominant parameter out of all the selected parameters. The developed mathematical model has been optimized using Response Surface Method to maximize the ultimate tensile strength. The weld joints fabricated using peak current of 7 Amps, back current of 4 Amps, pulse of 40 pulses/sec and pulse with of 50\% yielded superior ultimate tensile strength of $833 \mathrm{MPa}$ compared to the other joints.
\end{abstract}

Keywords: Pulsed current micro plasma arc welding, Inconel625, ultimate tensile strength, Design of Experiments, ANOVA, Response Surface Method

DOI: http://dx.doi.org/10.4314/ijest.v3i6.18

\section{Introduction}

In welding processes, the input parameters have greater influence on the mechanical properties of the weld joints. By varying the input process parameters, the output could be changed with significant variation in their mechanical properties. Accordingly, welding is usually selected to get a welded joint with excellent mechanical properties. To determine these welding combinations that would lead to excellent mechanical properties, different methods and approaches have been used. Various optimization methods can be applied to define the desired output variables through developing mathematical models to specify the relationship between the input parameters and output variables. One of the most widely used methods to solve this problem is response surface methodology (RSM), in which the unknown mechanism with an appropriate empirical model is approximated, being the function of representing a response surface method

Fusion welding generally involves joining of metals by application of heat for melting of metals to be joined. Almost all the conventional arc welding processes offer high heat input, which in turn leads to various problems such as burn through or melt trough, distortion, porosity, buckling warping \& twisting of welded sheets, grain coarsening, evaporation of useful elements present in coating of the sheets, joint gap variation during welding, fume generation form coated sheets etc (Balasubramanian.M et.al,2010). Micro Plasma arc Welding (MPAW) is a good process for joining thin sheet, but it suffers high equipment cost 
compared to GTAW. However it is more economical when compare with Laser Beam welding and Electron Beam Welding processes.

Pulsed current MPAW involves cycling the welding current at selected regular frequency. The maximum current is selected to give adequate penetration and bead contour, while the minimum is set at a level sufficient to maintain a stable arc (Balasubramanian et.al, 2006; Madusudhana et al., 1997). This permits arc energy to be used effectively to fuse a spot of controlled dimensions in a short time producing the weld as a series of overlapping nuggets. By contrast, in constant current welding, the heat required to melt the base material is supplied only during the peak current pulses allowing the heat to dissipate into the base material leading to narrower Heat Affected Zone (HAZ).

From the literature review ( Zhang.and Niu, 2000; Chi and Hsu, 2001; Hsiao et al., 2008; Siva et al., 2008; Lakshinarayana et al., 2008; Balasubramanian et al, 2009) it is understood that in most of the works reported the effect of welding current, arc voltage, welding speed, wire feed rate, magnitude of ion gas flow, torch stand-off, plasma gas flow rate on weld quality characteristics like front melting width, back melting width, weld reinforcement, welding groove root penetration, welding groove width, front-side undercut are considered. However much effort was not made to develop mathematical models to predict the same, especially when welding thin sheets are in a flat position. Hence, an attempt is made to correlate important pulsed current MPAW process parameters to ultimate tensile strength of the weld joints by developing mathematical model and optimize by using statistical tools such as design of experiments, analysis of variance and regression analysis.

\section{Experimental Procedure}

Inconel625 sheets of $100 \times 150 \times 0.25 \mathrm{~mm}$ are welded autogenously with square butt joint without edge preparation. The chemical composition of Inconel625 stainless steel sheet is given in Table 1. High purity argon gas (99.99\%) is used as a shielding gas and a trailing gas right after welding to prevent absorption of oxygen and nitrogen from the atmosphere. From the literature four important factors of pulsed current MPAW as presented in Table 2 are chosen. The welding has been carried out under the welding conditions presented in Table 3. A large number of trail experiments are carried out using 0.25mm thick Inconel625 sheets to find out the feasible working limits of pulsed current MPAW process parameters. Due to wide range of factors, it was decided to use four factors, five levels, rotatable central composite design matrix to perform the number of experiments for investigation. Table 4 indicates the 31 set of coded conditions used to form the design matrix. The first sixteen experimental conditions (rows) have been formed for main effects. The next eight experimental conditions are called as corner points and the last seven experimental conditions are known as center points. The method of designing such matrix is dealt elsewhere (Montgomery, 1991; Box et al., 1978; Balasubramanian et al., 2006). For the convenience of recording and processing the experimental data, the upper and lower levels of the factors are coded as +2 and -2 , respectively and the coded values of any intermediate levels can be calculated by using Equation-1 (Ravindra and Parmer, 1987, Siva et al., 2008). Fig.1 indicates the experimental setup used to carry out the experiments.

$$
X_{i}=2\left[2 X-\left(X_{\max }+X_{\min }\right)\right] /\left(X_{\max }-X_{\min }\right)
$$

Where $X_{i}$ is the required coded value of a parameter $X$. The $X$ is any value of the parameter from $X_{\min }$ to $X_{\max }$, where $X_{\min }$ is the lower limit of the parameter and $\mathrm{X}_{\max }$ is the upper limit of the parameter.

Table 1 Chemical composition of Inconel625 (weight \%)

\begin{tabular}{|c|c|c|c|c|c|c|c|c|c|c|c|c|c|c|}
\hline $\mathrm{C}$ & Mn & $\mathrm{P}$ & $\mathrm{S}$ & $\mathrm{Si}$ & $\mathrm{Cr}$ & $\mathrm{Ni}$ & $\mathrm{Al}$ & Mo & $\mathrm{Cb}$ & Ta & $\mathrm{Ti}$ & $\mathrm{N}$ & Co & $\mathrm{Fe}$ \\
\hline 0.0300 & 0.0800 & 0.0050 & 0.0004 & 0.1200 & 20.8900 & 61.6000 & 0.1700 & 8.4900 & 3.4400 & 0.0050 & 0.1800 & 0.0100 & 0.1300 & 4.6700 \\
\hline
\end{tabular}

Table 2 Important factors and their levels

\begin{tabular}{|c|c|c|c|c|c|c|c|}
\hline \multicolumn{9}{|c|}{ Levels } \\
\hline SI No & Input Factor & Units & -2 & -1 & 0 & +1 & +2 \\
\hline 1 & Peak Current & Amps & 6 & 6.5 & 7 & 7.5 & 8 \\
\hline 2 & Back Current & Amps & 3 & 3.5 & 4 & 4.5 & 5 \\
\hline 3 & Pulse & No's/sec & 20 & 30 & 40 & 50 & 60 \\
\hline 4 & Pulse width & $\%$ & 30 & 40 & 50 & 60 \\
\hline
\end{tabular}


Table 3 Welding conditions

\begin{tabular}{|c|c|}
\hline Power source & $\begin{array}{c}\text { Secheron Micro Plasma Arc Machine } \\
\text { (Model: PLASMAFIX 50E) }\end{array}$ \\
\hline Polarity & DCEN \\
\hline Mode of operation & Pulse mode \\
\hline Electrode & Argon \& thoriated tungsten electrode \\
\hline Electrode Diameter & 6 Lpm \\
\hline Plasma gas & Argon \\
\hline Plasma gas flow rate & 0.4 Lpm \\
\hline Shielding gas & Argon \\
\hline Shielding gas flow rate & 0.4 Lpm \\
\hline Purging gas & $1 \mathrm{~mm}$ \\
\hline Purging gas flow rate & $1 \mathrm{~mm}$ \\
\hline Copper Nozzle diameter & $260 \mathrm{~mm} / \mathrm{min}$ \\
\hline Nozzle to plate distance & Vertical \\
\hline Welding speed & Automatic \\
\hline Torch Position &
\end{tabular}

Table 4 Design matrix and experimental results

\begin{tabular}{|c|c|c|c|c|c|c|}
\hline SI No & $\begin{array}{l}\text { Peak Current } \\
\text { (Amps) }\end{array}$ & $\begin{array}{l}\text { Back current } \\
\text { (Amps) }\end{array}$ & $\begin{array}{c}\text { Pulse } \\
\text { (No/sec) }\end{array}$ & $\begin{array}{l}\text { Pulse width } \\
\text { (\%) }\end{array}$ & $\begin{array}{c}\text { Ultimate tensile } \\
\text { strength(UTS) } \\
\text { Actual(MPa) }\end{array}$ & $\begin{array}{l}\text { Ultimate tensile } \\
\text { strength(UTS) } \\
\text { Predicted(MPa) }\end{array}$ \\
\hline 1 & -1 & -1 & -1 & -1 & 833 & 834 \\
\hline 2 & 1 & -1 & -1 & -1 & 825 & 825 \\
\hline 3 & -1 & 1 & -1 & -1 & 838 & 838 \\
\hline 4 & 1 & 1 & -1 & -1 & 826 & 826 \\
\hline 5 & -1 & -1 & 1 & -1 & 826 & 826 \\
\hline 6 & 1 & -1 & 1 & -1 & 830 & 830 \\
\hline 7 & -1 & 1 & 1 & -1 & 825 & 825 \\
\hline 8 & 1 & 1 & 1 & -1 & 826 & 826 \\
\hline 9 & -1 & -1 & -1 & 1 & 825 & 825 \\
\hline 10 & 1 & -1 & -1 & 1 & 820 & 820 \\
\hline 11 & -1 & 1 & -1 & 1 & 835 & 835 \\
\hline 12 & 1 & 1 & -1 & 1 & 828 & 828 \\
\hline 13 & -1 & -1 & 1 & 1 & 818 & 818 \\
\hline 14 & 1 & -1 & 1 & 1 & 826 & 826 \\
\hline 15 & -1 & 1 & 1 & 1 & 824 & 824 \\
\hline 16 & 1 & 1 & 1 & 1 & 830 & 829 \\
\hline 17 & -2 & 0 & 0 & 0 & 830 & 830 \\
\hline 18 & 2 & 0 & 0 & 0 & 826 & 826 \\
\hline 19 & 0 & -2 & 0 & 0 & 821 & 821 \\
\hline 20 & 0 & 2 & 0 & 0 & 828 & 828 \\
\hline 21 & 0 & 0 & -2 & 0 & 832 & 832 \\
\hline 22 & 0 & 0 & 2 & 0 & 825 & 825 \\
\hline 23 & 0 & 0 & 0 & -2 & 831 & 831 \\
\hline 24 & 0 & 0 & 0 & 2 & 825 & 825 \\
\hline 25 & 0 & 0 & 0 & 0 & 830 & 833 \\
\hline 26 & 0 & 0 & 0 & 0 & 830 & 833 \\
\hline 27 & 0 & 0 & 0 & 0 & 840 & 833 \\
\hline 28 & 0 & 0 & 0 & 0 & 830 & 833 \\
\hline 29 & 0 & 0 & 0 & 0 & 838 & 833 \\
\hline 30 & 0 & 0 & 0 & 0 & 830 & 833 \\
\hline 31 & 0 & 0 & 0 & 0 & 834 & 833 \\
\hline
\end{tabular}




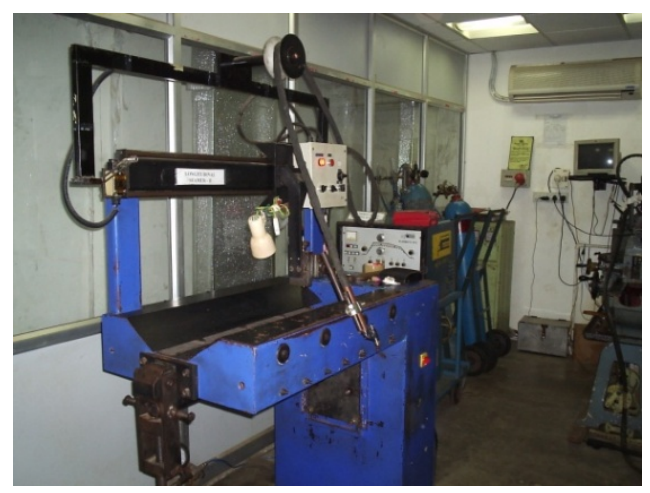

Fig.1 Experimental setup

\section{Measurement of Ultimate Tensile Strength}

Three transverse tensile specimens are prepared as per ASTM E8M-04 guidelines and the specimens after wire cut Electro Discharge Machining are shown in Fig.2 \& Fig.3. Tensile tests are carried out in 100kN computer controlled Universal Testing Machine (ZENON, Model No: WDW-100) as shown in Fig.4. The specimen is loaded at a rate of 1.5kN/min as per ASTM specifications, so that the tensile specimens undergo deformation. From the stress strain curve, the ultimate tensile strength of the weld joints is evaluated and the average of three results is presented in Table 4.

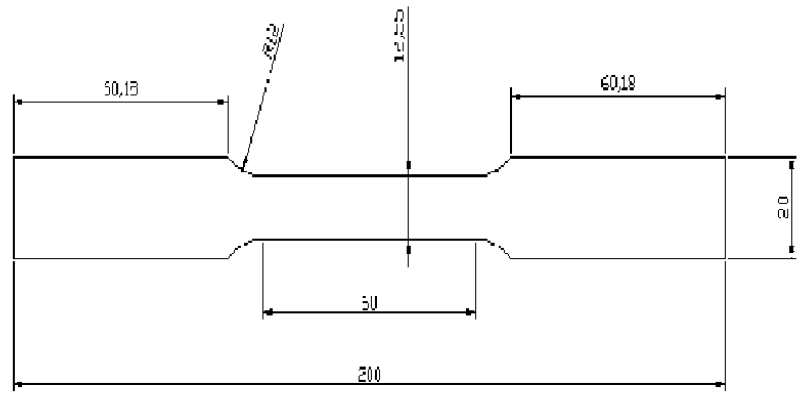

Fig.2 Dimensions of Tensile Specimen
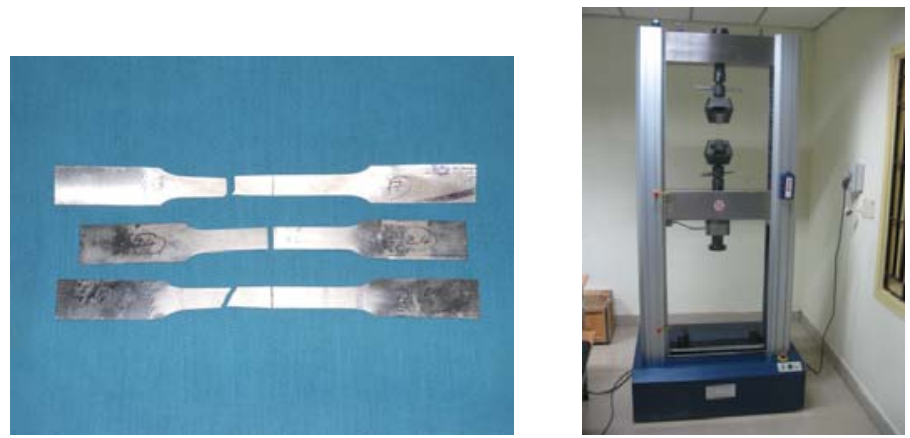

Fig.3 Tensile specimens

Fig.4 Universal Testing Machine

\section{Developing Mathematical Model}

The ultimate tensile strength of the weld joint is a function of peak current (A), back current (B), pulse (C) and pulse width (D). It can be expressed as (Cochran and Cox, 1957; Barker, 1985; Gardiner and Gettinby, 1998).

Ultimate tensile strength $(\mathrm{T})$

$\mathrm{T}=\mathrm{f}(\mathrm{A}, \mathrm{B}, \mathrm{C}, \mathrm{D})$

The second order polynomial equation used to represent the response surface ' $\mathrm{Y}$ ' is given by (Montgomery, 1991):

$\mathrm{Y}=\mathrm{b}_{\mathrm{o}}+\sum \mathrm{b}_{\mathrm{i}} \mathrm{x}_{\mathrm{i}}+\sum \beta_{\mathrm{ii}} \mathrm{x}_{\mathrm{i}}^{2}+\sum \sum \mathrm{b}_{\mathrm{ij}} \mathrm{x}_{\mathrm{i}} \mathrm{x}_{\mathrm{j}}+\epsilon$

Using MINITAB 14 statistical software package, the significant coefficients were determined and final models are developed using significant coefficients to estimate ultimate tensile strength values of weld joint. Details about estimated regression coefficients for ultimate tensile strength was presented in Table 5. 
Table 5 Estimated regression coefficients for ultimate tensile strength

\begin{tabular}{|c|c|c|c|c|c|}
\hline Term & Coef & SE Coef & $\mathrm{T}$ & $\mathrm{P}$ & Remarks \\
\hline Constant & 833.143 & 1.0027 & 830.894 & 0.000 & Significant \\
\hline Peak Current & -0.875 & 0.5415 & -1.616 & 0.126 & Insignificant \\
\hline Back Current & 1.792 & 0.5415 & 3.309 & 0.004 & Significant \\
\hline Pulse & -1.625 & 0.5415 & -3.001 & 0.008 & Significant \\
\hline Pulse Width & -1.458 & 0.5415 & -2.693 & 0.016 & Significant \\
\hline Peak Current*Peak Current & -1.296 & 0.4961 & -2.613 & 0.019 & Significant \\
\hline Back Current*Back Current & -2.171 & 0.4961 & -4.376 & 0.000 & Significant \\
\hline Pulse*Pulse & -1.171 & 0.4961 & -2.361 & 0.031 & Insignificant \\
\hline Pulse Width * Pulse Width & -1.296 & 0.4961 & -2.613 & 0.019 & Significant \\
\hline Peak Current*Back Current & -0.688 & 0.6632 & -1.037 & 0.315 & Insignificant \\
\hline Peak Current*Pulse & 3.187 & 0.6632 & 4.806 & 0.000 & Significant \\
\hline Peak Current*Pulse Width & 1.063 & 0.6632 & 1.602 & 0.129 & Insignificant \\
\hline Back Current*Pulse & -1.187 & 0.6632 & -1.790 & 0.092 & Insignificant \\
\hline Back Current*Pulse Width & 1.688 & 0.6632 & 2.544 & 0.022 & Insignificant \\
\hline Pulse*Pulse Width & 0.312 & 0.6632 & 0.471 & 0.644 & Insignificant \\
\hline S = 2.653 R-Sq $=85.8 \%$ & R-Sq(adj) $=73.3 \%$ & & \\
\hline
\end{tabular}

The final mathematical model are given by

Ultimate tensile strength $(\mathrm{T})$

$\mathrm{T}=833.143-0.875 \mathrm{X}_{1}+1.792 \mathrm{X}_{2}-1.625 \mathrm{X}_{3}-1.458 \mathrm{X}_{4}-1.296 \mathrm{X}_{1}^{2}-2.171 \mathrm{X}_{2}^{2}-1.296 \mathrm{X}_{4}^{2}+3.187 \mathrm{X}_{1} \mathrm{X}_{3}$

Where $\mathrm{X}_{1}, \mathrm{X}_{2}, \mathrm{X}_{3}$ and $\mathrm{X}_{4}$ are the coded values of peak current, back current, pulse and pulse width.

\section{Checking the adequacy of the developed model}

The adequacy of the developed model was tested using the analysis of variance technique (ANOVA). As per this technique, if the calculated value of the $F_{\text {ratio }}$ of the developed model is less than the standard $F_{\text {ratio }}$ (from F-table) value at a desired level of confidence (say 99\%), then the model is said to be adequate within the confidence limit. ANOVA test results presented in Table 6 are found to be adequate at $99 \%$ confidence level. The value of co-efficient of determination ' $\mathrm{R}^{2}$ ' for the above developed model is found to be about 0.86 .

Fig. 5 indicates the scatter plots for ultimate tensile strength of the weld joint and reveals that the actual and predicted values are close to each other with in the specified limits. Predicted values for all the 31 samples were presented in Table 4.

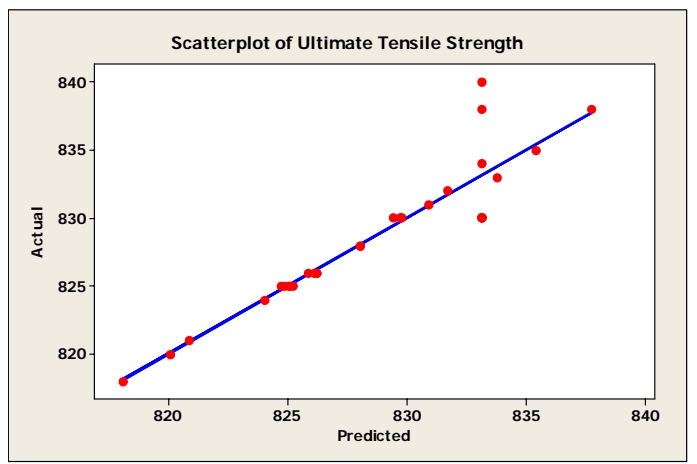

Fig.5 Scatter plot of ultimate tensile strength 
Table.6 ANOVA test results of ultimate tensile strength

\begin{tabular}{|c|l|l|l|l|l|l|}
\hline \multicolumn{7}{|c|}{ Ultimate tensile strength } \\
\hline Source & DF & Seq S & Adj SS & Adj MS & F & P \\
\hline Regression & 14 & 679.070 & 679.070 & 48.5050 & 6.89 & 0.000 \\
\hline Linear & 4 & 209.833 & 209.833 & 52.4583 & 7.45 & 0.001 \\
\hline Square & 4 & 211.362 & 211.362 & 52.8405 & 7.51 & 0.001 \\
\hline Interaction & 6 & 257.875 & 257.875 & 42.9792 & 6.11 & 0.002 \\
\hline Residual Error & 16 & 112.607 & 112.607 & 7.0379 & & \\
\hline Lack-of-Fit & 10 & 1.750 & 1.750 & 0.1750 & & \\
\hline Pure Error & 6 & 110.857 & 110.857 & 18.4762 & 0.01 & 1.000 \\
\hline Total & 30 & 791.677 & & & & \\
\hline
\end{tabular}

Confirmation tests are carried out different conditions to check the accuracy of the developed model. The details of confirmation tests is shown in Table.7

Table.7 Confirmation of test results

\begin{tabular}{|c|c|c|c|c|c|c|c|c|c|}
\hline $\begin{array}{c}\text { Peak } \\
\text { Current }\end{array}$ & $\begin{array}{c}\text { Back } \\
\text { Current }\end{array}$ & Pulse & $\begin{array}{c}\text { Pulse } \\
\text { Width }\end{array}$ & $\begin{array}{c}\text { Peak Current } \\
\text { (Amps) }\end{array}$ & $\begin{array}{c}\text { Back } \\
\text { current } \\
\text { (Amps) }\end{array}$ & $\begin{array}{c}\text { Pulse } \\
\text { (No/sec) }\end{array}$ & $\begin{array}{c}\text { Pulse } \\
\text { width } \\
(\%)\end{array}$ & $\begin{array}{c}\text { Experimental } \\
\text { Values of UTS } \\
\text { (MPa) }\end{array}$ & $\begin{array}{c}\text { Predicted values } \\
\text { of UTS (MPa) }\end{array}$ \\
\hline 2 & 2 & 2 & 2 & 8 & 5 & 60 & 70 & 820 & 823 \\
\hline-2 & -2 & -2 & -2 & 6 & 3 & 20 & 30 & 828 & 831 \\
\hline 0 & 2 & 2 & 2 & 7 & 5 & 60 & 70 & 810 & 817 \\
\hline 2 & 0 & 2 & 2 & 8 & 4 & 60 & 70 & 824 & 828 \\
\hline 2 & 2 & 0 & 2 & 8 & 5 & 40 & 70 & 808 & 813 \\
\hline 2 & 2 & 2 & 0 & 8 & 5 & 60 & 50 & 828 & 831 \\
\hline 0 & -2 & -2 & -2 & 7 & 3 & 20 & 30 & 816 & 822 \\
\hline-2 & 0 & -2 & -2 & 6 & 4 & 20 & 30 & 836 & 843 \\
\hline-2 & -2 & 0 & -2 & 6 & 3 & 40 & 30 & 812 & 815 \\
\hline-2 & -2 & -2 & 0 & 6 & 3 & 20 & 50 & 832 & 833 \\
\hline
\end{tabular}

From Table 6 it is very clear that the developed model holds good for set of input parameters other than that specified in RSM design matrix. However it is important that the developed model is valid with in the range of weld input parameters.

\section{Effect of process variables on output response}

Contour plots play a very important role in the study of the response surface. By generating contour plots using software (MINITAB14) for response surface analysis, the optimum is located by characterizing the shape of the surface. If the counter patterning of circular shaped counters occurs, it tends to suggest the independence of factor effects; while elliptical contours may indicate factor interaction. Fig's 6a to $6 \mathrm{f}$ represents the contour plots for ultimate tensile strength. From the contour plots, the interaction effect between the input process parameters and output response can be clearly analyzed.

From the contour plot in Fig.6a, for optimum ultimate tensile strength of pulsed current MPAW Inconel625 nickel alloy, the tensile strength is more sensitive to change in peak current than in the back current. From the contour plot in Fig.6b, it can be seen that ultimate tensile strength is sensitive to both pulse and peak current. From the contour plot in Fig.6c, it can be seen that ultimate tensile strength is more sensitive to peak current than pulse width. From the contour plot in Fig.6d, it can be seen that ultimate tensile strength is more sensitive to pulse than back current. From the contour plot in Fig.6e, it can be seen that ultimate tensile strength is more sensitive to pulse width than back current. From the contour plot in Fig.6f, it can be seen that ultimate tensile strength is more sensitive to pulse than pulse width. From all the contour plots it is understood that peak current and pulse are the most important parameters which affect the ultimate tensile strength of the welded joints. 


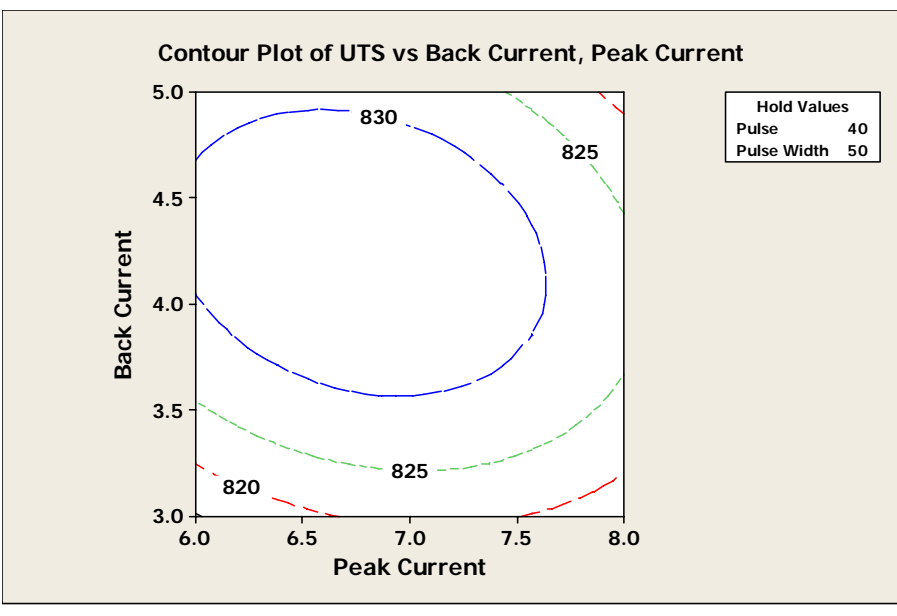

Fig.6a

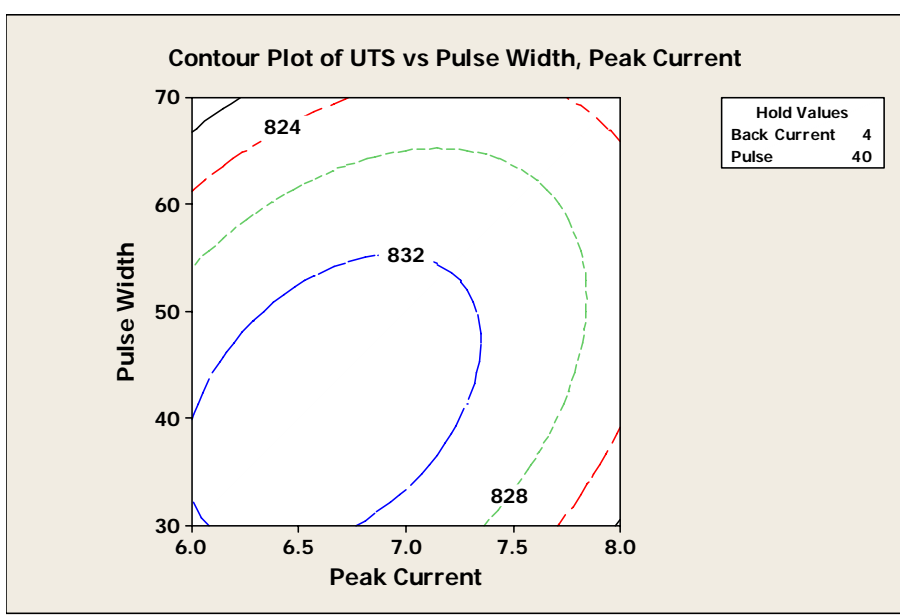

Fig.6c

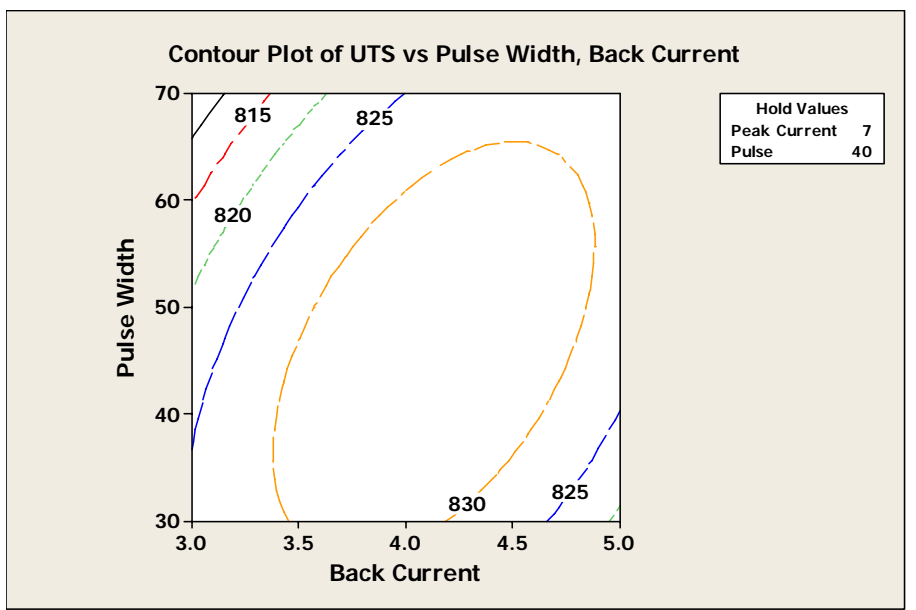

Fig.6e

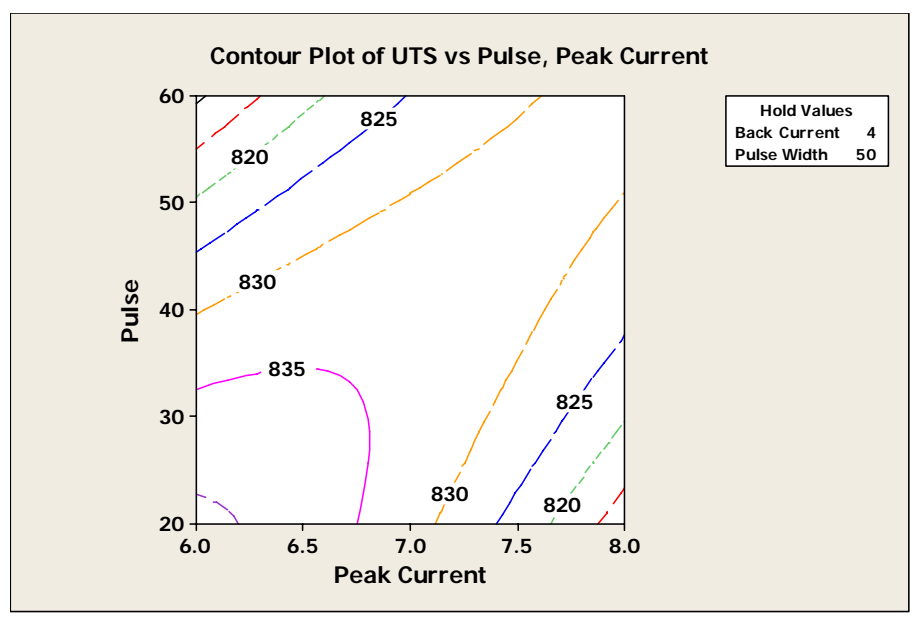

Fig.6b

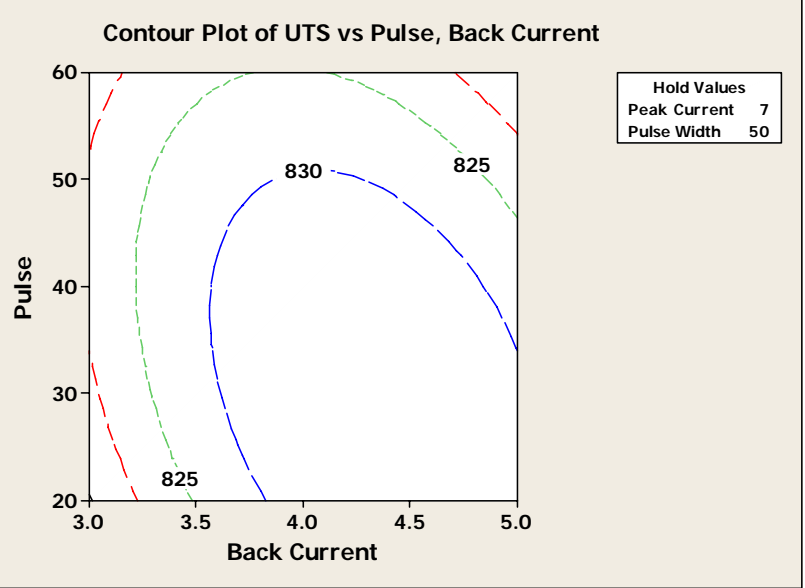

Fig.6d

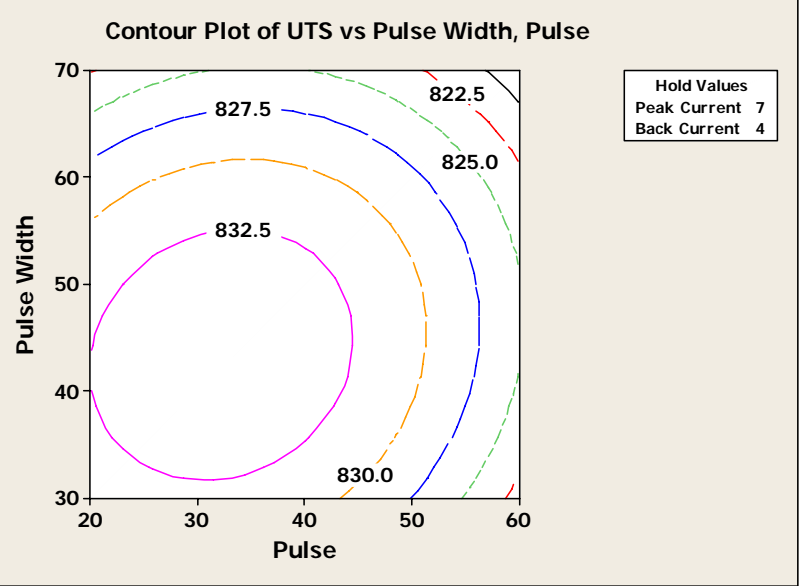

Fig.6f

Response Surface plots clearly indicate the optimal response point. The optimum ultimate tensile strength of pulsed current MPAW welded Inconel625 nickel alloy was exhibited by the apex of the response surface, as shown in Fig.7a to Fig.7f .

Fig.7a shows the three dimensional response surface lot for ultimate tensile strength obtained from the regression model, assuming a peak current of 7 Amps and a back current of about 4.5Amps. The optimum ultimate tensile strength is exhibited by 
the apex of the response surface. From the response graph, it is identified that at the peak current of 7 Amps, the ultimate tensile strength of pulsed current MPAW joints is higher. The formation of fine equiaxed grains in fusion zone increases the ultimate tensile strength of the welded joints. When peak current is increased from 7 Amps, the ultimate tensile strength deceases. This is the result of the increased heat input associated with the use of higher peak current. The formation of coarser grains in the fusion zone is responsible for the lower ultimate tensile strength of the welded joints. This phenomenon can also be explained by the change in cooling rate. Moreover, the slower the cooling the during solidification, the longer the time available for grain coarsening. In contrast, the decrease in peal current leads to the decrease in the heat input, which leads to faster cooling rate and subsequently finer grain size in fusion zone (Kumar et al., 2007).

Fig.7b depicts the three dimensional response surface plot for the response ultimate tensile strength obtained from the regression model, assuming pulse of 40pulse/sec and peak current of 7Amps. From the response graph, it is observed that when the pulse is 20pulse/sec, the ultimate tensile strength of the pulsed current MPAW welded joint is higher. When the pulse is increase to 60 pulse/sec, the ultimate tensile strength is decreased. The finer grain size of fusion zone is responsible for the increase in ultimate tensile strength of the welded joints. At very low pulses, the effect of pulsing on the weld bead is less compared to that at high frequency pulsing. It is also true that mechanical and thermal disturbances to the weld pool at low pulse are expected to be less intense. At high pulse, the vibration amplitude and temperature oscillation induced on the weld pool are reduced to a greater extent resulting in reduced effect on the weld pool. Moreover, at high pulse values, the molten pool is agitated violently, resulting in grain refinement in the weld region (Kou and Le, 1986). Hence there exists an optimum pulse at which the grain refinement is maximum. In this investigation, the optimum pulse is found to be 40 pulse/sec.

Fig.7c shows the three dimensional response surface plot for the response ultimate tensile strength obtained from the regression model, assuming pulse width of $50 \%$ and peak current of 7 Amps. From the response graph, it is identified that at the pulse width of $50 \%$, the ultimate tensile strength of pulsed current MPAW welded joints is higher. The fine grains observed in the fusion zone may be responsible for higher tensile strength of the welded joints. The pulse width increases further, which promotes the grain growth on the weld region. This is because as the pulse on time increases, the period from the start of a pulse to the end of the base time also increases. When pulse width is increased, the welding heat has more time to conduct into the fusion zone, which promotes grain coarsening (Senthil Kumar.T, 2007). The grains in fusion zone get coarser, with increasing pulse on time and the ultimate tensile strength of these welded joints decreases.

Fig.7d shows the three dimensional response surface plot for the response ultimate tensile strength obtained from the regression model, assuming a base current of 4 Amps and pulse of 40 pulses/sec. From the surface graph, it is observed that when the base current is 4 Amps, the ultimate tensile strength of pulsed current MPAW welded joints is higher. The fine grains observed in the fusion zone due to optimum heat input may be responsible for the better tensile strength of welded joints. When the back current increases to 5Amps, the tensile strength decreases. The grain coarsening deteriorates the ultimate tensile strength of these welded joints.

Fig.7e shows the three dimensional response surface plot for the response ultimate tensile strength obtained from the regression model, assuming a back current of 4 Amps and pulse width of 50\%. From the graph, it is observed that when the back current is 4 Amps, the ultimate tensile strength of pulsed current MPAW welded joints is higher.

Fig.7f shows the three dimensional response surface plot for the response ultimate tensile strength obtained from the regression model, assuming pulse of 40 pulses/sec and pulse width of 50\%. From the response graph, it is observed that when pulse is 40pulse/sec, the tensile strength of the pulsed current MPAW welded joint is higher. The fine grains observed in the fusion zone due to optimum heat input may be responsible for the better ultimate tensile strength of these welded joints.

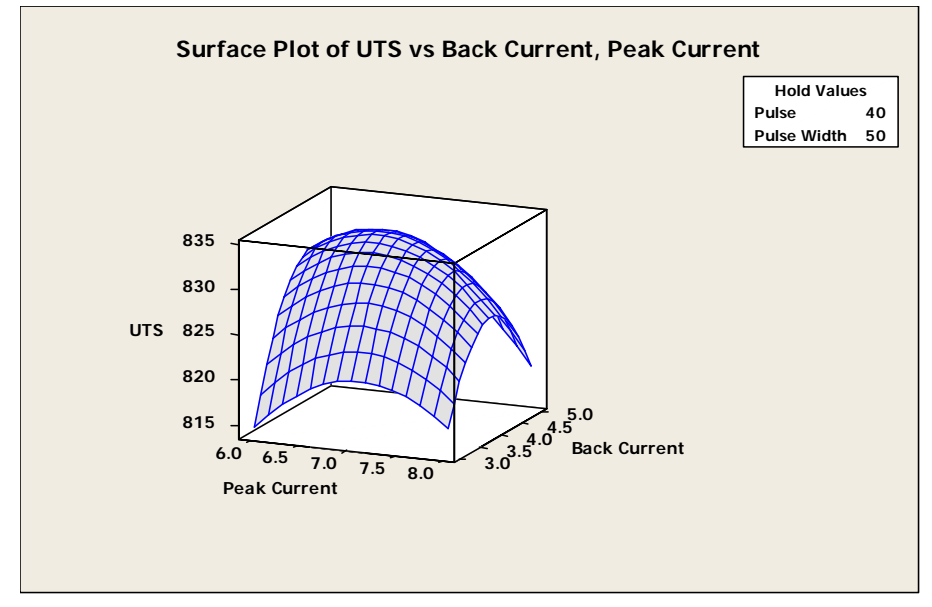

Fig.7a

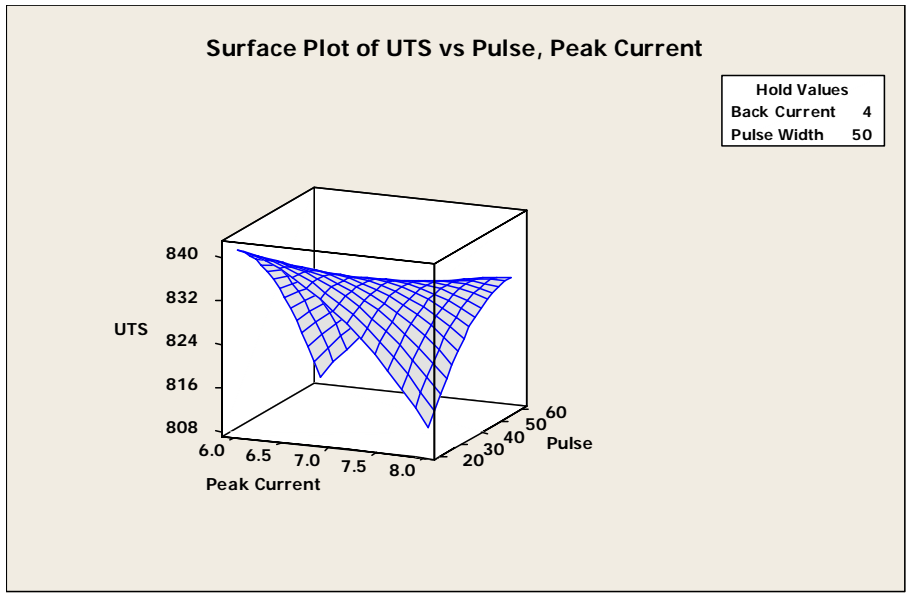

Fig.7b 


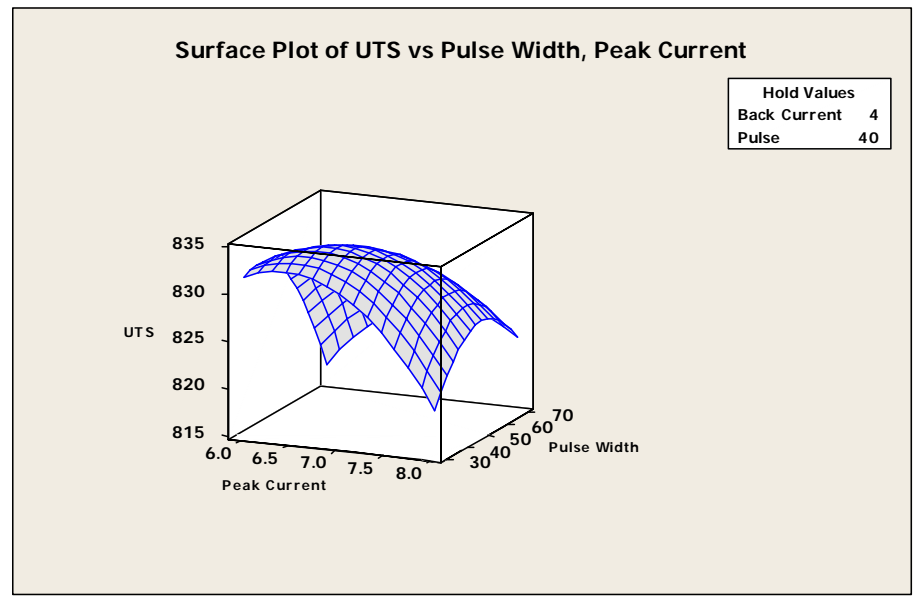

Fig.7c

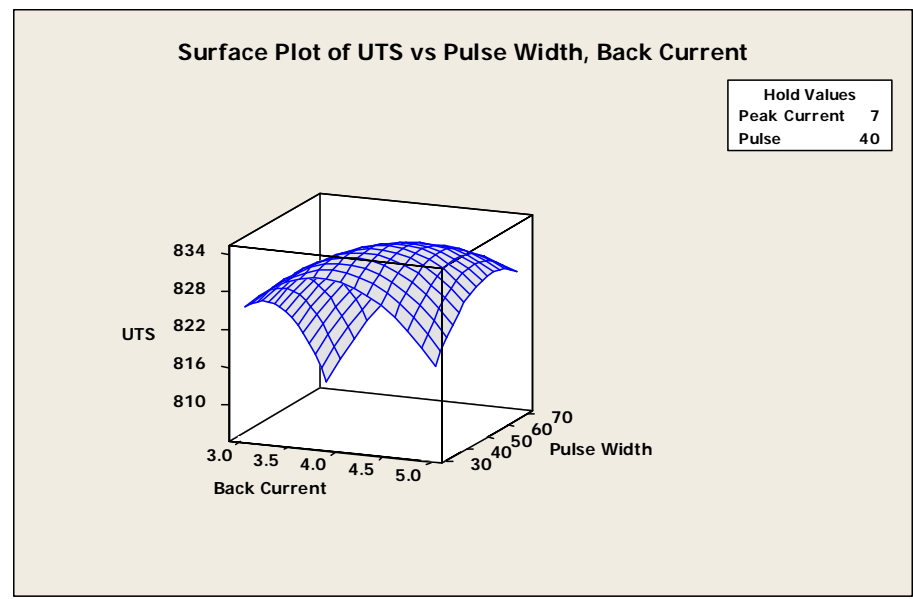

Fig.7e

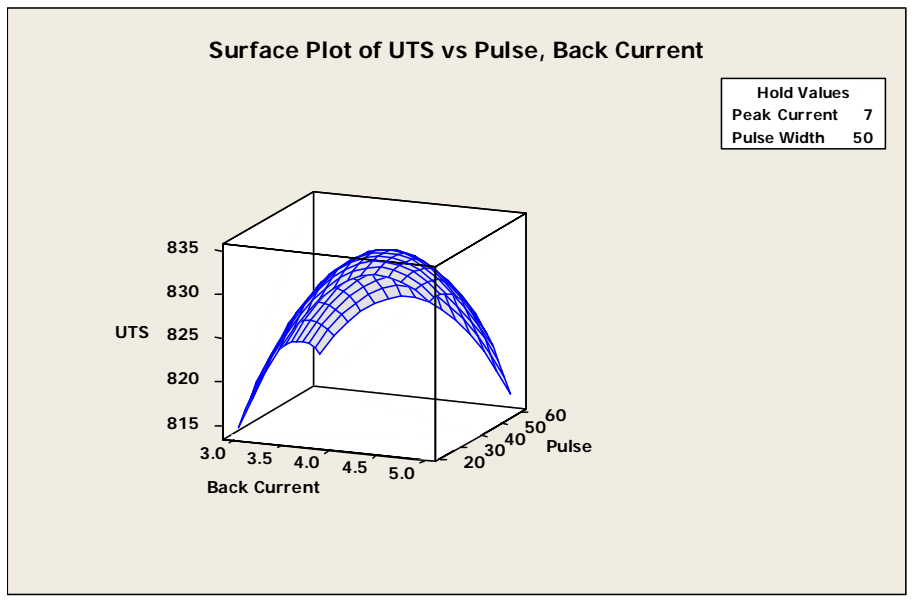

Fig.7d

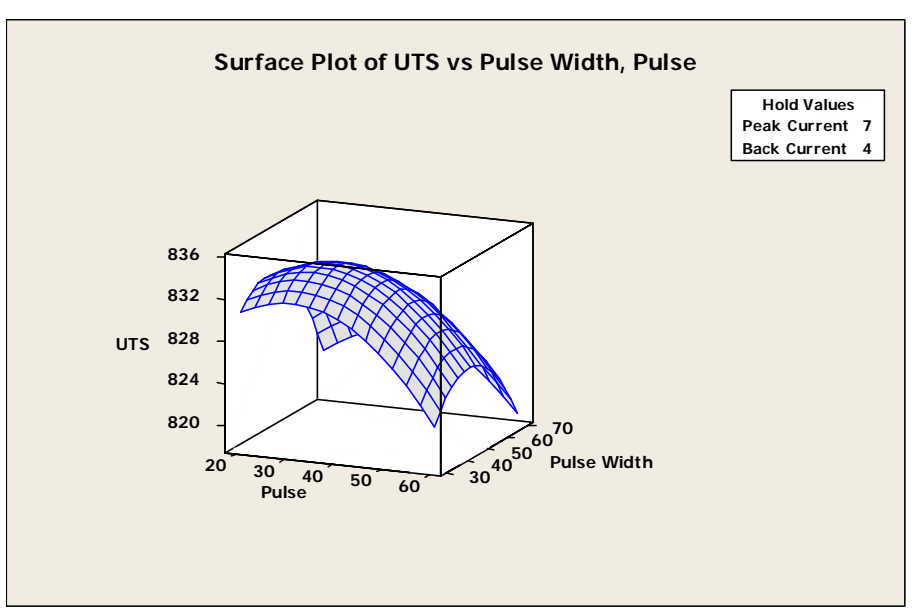

Fig.7f

Fig.8 indicates the grain structure of parent metal and fusion zone of Inconel 625 welded joint. It was observed that the grain size of fusion zone is smaller than the parent metal zone. This shows the ultimate tensile strength along the fusion zone is more than that of parent metal

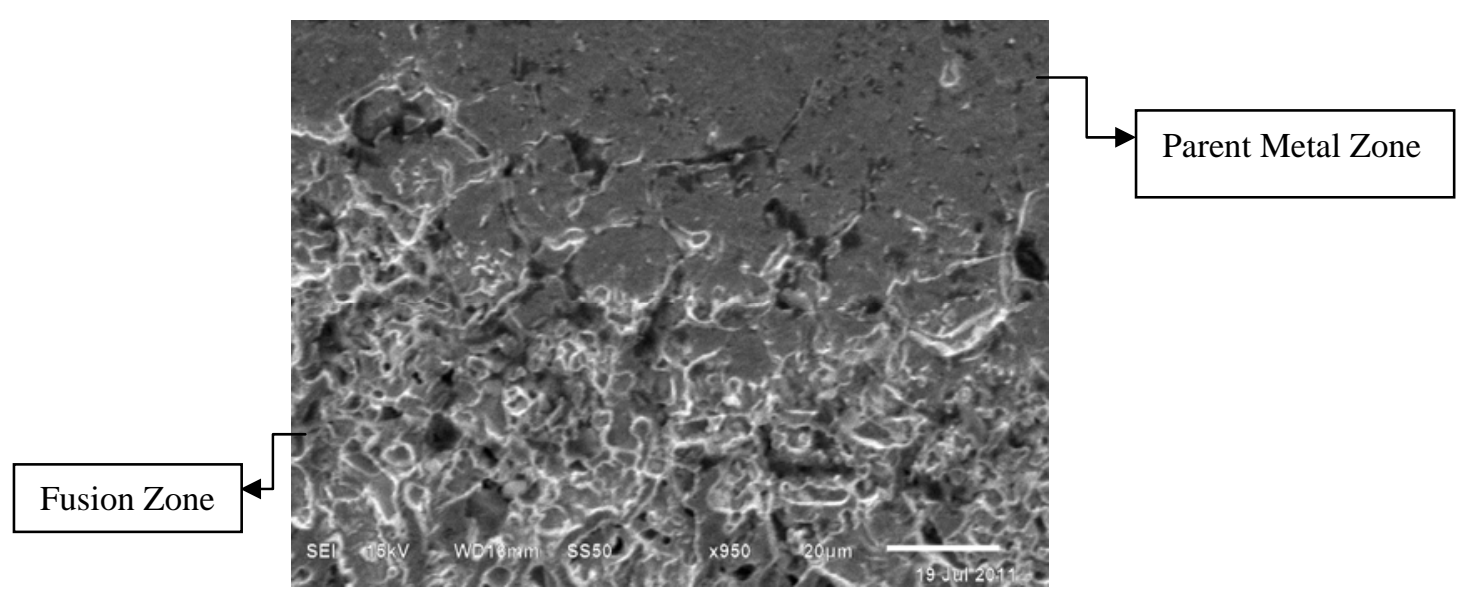

Fig.8 SEM image of Inconel 625 welded joint 


\section{Optimization of pulsed current MPAW process parameters}

The response surface method (RSM) was used as an optimization tool to search the optimum values of the process variables. The mathematical model developed in section 4was framed using the coded values. The optimization was done on coded values and then converted to actual values. MINITAB 14 software was used to optimize the process variables. The optimum values predicted by RSM , Hooke \& Jeeves Method and experimentally obtained are listed in Table 8.The values obtained in RSM are only approximate values based on surface plots. For better results one has to go for advanced optimization techniques like Neural Networks, Genetic Algorithm.etc

Table 8 Comparison of optimum values

\begin{tabular}{|c|c|c|c|}
\hline Parameter & Predicted by RSM & $\begin{array}{c}\text { Hooke \& Jeeves } \\
\text { Method }\end{array}$ & Experimental \\
\hline Peak current(Amps) & 7 & 7.2177 & 7 \\
\hline Back current(Amps) & 4 & 4.2177 & 4 \\
\hline Pulse (no/sec) & 40 & 44.3545 & 40 \\
\hline Pulse width(\%) & 50 & 54.3545 & 50 \\
\hline Maximum ultimate tensile strength(Mpa) & 833 & 844.3545 & 840 \\
\hline
\end{tabular}

\section{Conclusions}

Empirical relation is developed to predict ultimate tensile strength of pulsed current micro plasma arc welded Inconel 625 nickel alloy using response surface method. The developed model can be effectively used to predict ultimate tensile strength of pulsed current micro plasma arc welded joints. The model is validated using validation experiments and found to be satisfactory. Contour plots are drawn to study the interaction effects of weld parameters and it is understood that ultimate tensile strength is more sensitive to peak current and pulse. Surface plots are drawn to identify the optimum value of ultimate tensile strength and it is found that for welding conditions of peak current of 7Amps, back current of 4 Amps, pulse of $40 \mathrm{no} / \mathrm{sec}$ and pulse width of $50 \%$, the optimum ultimate tensile strength obtained is $833 \mathrm{MPa}$, where as the actual value is about $840 \mathrm{MPa}$.

\section{Acknowledgments}

The authors would like to thank Shri. R.Gopla Krishnan, Director, M/s Metallic Bellows (I) Pvt Ltd, Chennai, India for his support to carry out experimentation work.

\section{References}

Balasubramanian.M, Jayabalan.V, Balasubramanian.V, 2010, Effect of process parameters of pulsed current tungsten inert gas welding on weld pool geometry of titanium welds, Acta Metall.Sin.(Engl. Lett.),Vol.23, No.4,p. 312.

Balasubramanian.V, Lakshminarayanan.A.K, Varahamoorthy.R and Babu.S, 2009, Application of Response Surface Methodology to Prediction of Dilution in Plasma Transferred Arc Hardfacing of Stainless Steel on Carbon Steel , Science Direct, Vol.16, No.1,p.44.

Balasubramanian.B, Jayabalan.V, Balasubramanian.V, 2006, Optimizing the Pulsed Current Gas Tungsten Arc Welding Parameters, J Mater Sci Technol, Vol.22, No.6, p.821.

Barker T B, 1985, Quality by experimental design, ASQC Quality Press, Marcel Dekker.

BoxG EP, Hunter W H, Hunter J S, 1978, Statistics for experiments, New York: John Wiley \& Sons, p.112.

Cochran W G, Cox G M, 1957, Eperimental Designs, John Wiley \& Sons Inc, London.

Gardiner W P, Gettinby G, 1998, Experimental design techniques in statistical practice, Horwood press, Chichester.

Hsiao.Y.F, Tarng.Y.S, and Wang. J, 2008,Huang Optimization of Plasma Arc Welding Parameters by Using the Taguchi Method with the Grey Relational Analysis, Journal of Materials and Manufacturing Processes, Vol.23,p.51.

Kumar.S, Kumar.P, Shan.H.S, 2007, Effect of evaporative casting process parameters on the surge roughness of Al-7\%Si alloy casting, J Mater Proc Techno, Vol.18, No.2,p 615.

Kou S, Le Y, 1986, Nucleation mechanism and grain refining of weld metal, Weld J, p.65.

Lakshinarayana A.K, Balasubramanian.V, Varahamoorthy.R and Babu.S, 2008, Predicted the Dilution of Plasma Transferred Arc Hardfacing of Stellite on Carbon Steel using Response Surface Methodology, Metals and Materials International, Vol.14, No.6, p.779.

Madusudhana Reddy G, Gokhale A A, Prasad Rao K, 1997, Weld microstructure refinement in a 1441 grade aluminium-lithium alloy, Journal of Material Science, Vol.32, No.5, p.4117.

Montgomery D.C, 1991, Design and analysis of experiments, 3rd Edition, New York, John Wiley \& Sons, p.291. 
Ravindra J \& Parmar R S, 1987, Mathematical model to predict weld bead geometry for flux cored arc welding, Journal of Metal Construction, p.45.

Siva.K, Muragan.N, Logesh.R, 2008,Optimization of weld bead geometry in Plasma transferred arc hardfacing austenitic stainless steel plates using genetic algorithm, Int J Adv Manuf Technol, Vol.41, No’s 1-2,p.24.

Senthil Kumar.T, Balasubramanian.V, Sanavullah M.Y, 2007, Influences of pulsed current tungsten inert gas welding parameters on the tensile properties of AA 6061 aluminum alloy, Materials and Design, Vol.28, p.2080.

Sheng-Chai Chi, LI-Chang Hsu ,2001, A fuzzy Radial Basis Function Neural Network for Predicting Multiple Quality characteristics of Plasma Arc Welding, IEEE,0-7803-7078-3,,No.01,p.2807.

Zhang.D.K and Niu.J.T ,2000,Application of Artificial Neural Network modeling to Plasma Arc Welding of Aluminum alloys, Journal of Advanced Metallurgical Sciences, Vol.13, No.1, p.194.

\section{Biographical notes}

K.Siva Prasad is currently an Assistant Professor in the Department of Mechanical Engineering, Anil Neerukonda Institute of Technology \& Sciences, Visakhapatnam,India. He graduated in Mechanical Engineering from Vasavi Engineering College (Affiliated to Osmania University, Hyderabad) in 2000. He received his Masters Degree from JNTU Hyderabad, India in 2002. He has published 3 research papers in International Journals and various papers in International and National conferences.

Ch.Srinivasa Rao is currently an Associate Professor in the Department of Mechanical Engineering, Andhra University, Visakhapatnam, India. He graduated in Mechanical Engineering from SVH Engineering College, Machilipatnam,, India in 1988. He received his Masters Degree from MANIT, Bhopal, India in 1991. He received PhD from Andhra University in 2004. He has published over 25 research papers in refereed journals and conference proceedings.

D. Nagesawara Rao worked as a Professor in Andhra University, Visakhapatnam, India for past 30 years and presently he is working as Vice Chancellor, Centurion University, Orissa, India. Under his guidance 18 PhD's were awarded. He has undertaken various projects sponsored by UGC, AICTE and NRB. He worked as a coordinator for Centre for Nanotechnology, Andhra University, Visakhapatnam.

Received August 2011

Accepted November 2011

Final acceptance in revised form December 2011 